\title{
Механизми на зараждане на тинитус
}

\author{
С. Върбанова, Д. Попова \\ Медицински университет - София \\ Катедра по УНГ-болести \\ УМБАЛ „Царица Йоанна - ИСУЛ“ЕАД - София
}

\begin{abstract}
The frequency of the Tinnitus phenomenon has increased over the last decades. This is in connection with the development of human civilization, the ever changing environment and way of life and the increased number of diseases of wide social importance. We propose here a review of contemporary theories regarding the genesis, development, consequences and treatment methods of chronic Tinnitus.
\end{abstract}

\section{Резюме}

Честотата на Tinnitus се увеличава през последните десетилетия. Това е във връзка с развитието на човешката цивилизация, променящия се начин на живот, влиянието на околната среда и нарастването на броя и на социално значимите заболявания. Предлагаме преглед на съвременните теории за генезата, развитието, последиците и методите на лечение на хроничния Tinnitus.

\section{Увод}

През последните десетилетия честотата на феномена Tinnitus нараства, с което се засилва и научният интерес към него. Това е във връзка с развитието на човешката цивилизация, променящия се начин на живот и на околната среда и нарастването на броя и на социално значимите заболявания.

От 1966 г. в Pubmed могат да се намерят около 4000 разработки, които представят неврофизиологични аспекти, теории за патофизиологията, психологични ефекти, предлагат различни форми на лечение и резултати от клинични наблюдения и оценки.

През 1987 година Tinitology е дефинирана като област от науката, изучаваща механизмите на зараждане на субективния шум в ушите. Определението за същността на Tinnitus се основава на възприемането на звук при липса на акустична стимулация от външен източник. Това е симптом, а не заболяване и има много различни причини, дължащи се на неспецифични лезии в слуховата и централната нервна система.

\section{Честота}

Шумът в ушите най-често съпровожда двустранната приемна слухова загуба, което потвърждава и теорията за периферната му генеза. Увеличаването на риска се регистрира при настъпване на метаболитни и спондилозни промени във възрастта над 55 години.

Според Noell, Meyerhoff (2003) и Marion, Gevette (1991) повече от 37 милиона в Америка страдат от Tinnitus, като най-често е засегната възрастта между 40 и 70 години. Britich Tinnitus Association в проучванията 
си регистрира, че един от 10 анкетирани страда от Tinnitus.

Като причини се описват проводни и приемни слухови нарушения, неврологични и метаболитни заболявания, психични проблеми и психогенни разстройства.

Според някои теории за произхода на Tinnitus като генератори се определят периферната и централна слухови системи (SOAE, Presbyacusis, дорзалното кохлеарно ядро, слуховата пластичност, соматосензорната и лимбична системи).

Предлага се преглед на съвременните теории за генезата, развитието, последиците и методите на лечение на хроничния Tinnitus.

Baguley DM (2002): Разглежда последните теории и концепции, свързани с възприемането на $\mathrm{T}$, и приема следните механизми на зараждането на tinnitus:

- Увреда на структурите на вътрешното ухо.

- Биохимични промени в слуховата система.

- Синхронизирана спонтанна активност в кохлеарния нерв.

Kaltenbach JA, Zhang J, Finlayson P. (2005):

- DCN става хиперактивен център след въздействието на интензивни звуци или цисплатина.

- Регистрират се пластични промени като последица от периферни увреди - променящо се поведение и химическата активност в невроните на DCN, докато други могат да бъдат стимулирани от слухови и неослухови структури.

- Паралельт между различните форми на пластичност при T и DCN подкрепя хипотезата, че последното играе важна роля в генерирането и модулирането на сигнали, продуциращи Т.

Zenner HP, Pfister M, Birbaumer N. (2006):

- Определят централния Т като най-често срещащ се от хроничните.

- Приемат, че се създават нови невронни връзки в мозъка на базата на променената входяща стимулация от вътрешното ухо.

- Допускат, че неврофизиологичен модел може да обясни симптомите, причинени от централни когнитивни смущения и възприемането на шумове, причинени от постоянни неврофизиологични отклонения.

- Условните рефлекси, отговорни за вече угаснали функции, могат да доведат до порочен кръг от свръхвъзбуда в слуховата система.

- Друга проява на тази малфункция са и познавателните и поведенчески отклонения.
Müller A R. (2006):

- Разглежда двата различни вида, като обективният $\mathrm{T}$ се причинява от звукови генератори в тялото, докато субективният $\mathrm{T}$ е резултат от непривична невронална активност, непровокирана от звук.

- При повечето форми на Т анатомичната локализация на физиологични абнормалитети е в ЦНС, въпреки че чувството се отнася за едното или двете уши.

- Причина за повечето форми на субективен Т са промени, появяващи се в резултат от изявата на невралната пластичност, като форма на препрограмиране на мозъка, независещо от желанието на индивида.

- Т често се появява със слухова загуба, доказателство, че невралната пластичност е свързана с липсата на входен сигнал.

- Т може да бъде съпроводен и с hyperacusis, a понякога и phonophobia и депресия, показателни за изменящи се процеси при постьпването и обработването на слуховата информация.

- Представя доказателства, че някои форми на T са свързани с включване на нетрадиционни слухови пътища (извънлемнискусни, дифузни или полисензорни), които заобикалят първичната слухова церебрална кора и осигуряват подкорова връзка с лимбичните структури.

Richard Tylor, Claudio Coelho, William Noble (2006):

- Обръщат особено внимание на емоционалното състояние на пациенти, страдащи от T.

- Приемат, че има обща генетична причина за Т и депресията и това е генът за транспорт на серотонина SL C6 A4

De Ridder D, Van de Heyning P. (2007) приемат, че:

- Невралната пластичност е форма на адаптация при естествения подбор, при която клетки или клетъчни групи са лишени от естествената стимулация и търсят активно информация за преживяване.

- Дарвиновият модел за мозъчна пластичност може да обясни симптомите, предизвикани от променената стимулация.

- Основавайки се на сензорната пластичност, която причинява симптомите и белезите на различни заболявания, може да се стигне до създаването, прилагането на ново лечение при симптоми, предизвикани от липсата на адекватна стимулация. То се състои в електриче- 
ска и магнитна стимулация на слуховата и соматосензорната кора за лечение на $\mathrm{T}$, което подкрепя Дарвиновата хипотеза за невралната пластичност.

\section{Saunders JC (2007):}

- Свързва Т с промените в невропластичността на мозъка.

- Допуска, че в резултат от взаимодействието между много и различни мозъчни полета в мозъка има предилекции, свързани с Т.

- Установява, че Т при неврофизиологичния модел се усилва от влияния на ЦНС и пластичните промени в първичните и непървични слухови пътища, което е от значение за последващите тежест на възприемане и променена емоционалност.

- Тези пластични промени се предизвикват от периферни увреди, които водят до нов вид мозъчна активност поради анатомично изменение на връзките между невроните в ЦНС.

- Тези промени могат да променят баланса между възбудните и задръжни процеси в мозъка и да предизвикат каскада от последваща невронална активност между ствола и кората по начин, който предизвиква изпитването на тинитус.

- Свързани с Т, поведенческите промени са комплекс от биологически промени и промени в невропластичността на мозъка.

- Непотискането на спонтанната активност, невралната синхронизация и тонотопичната реорганизация могат да повлияят T.

Müller AR. (2007):

- Приема, че патофизиологията на едностранния и двустранен Т е различна.

- Определя централна роля, която невралната пластичност играе в зараждането на хроничния субективен Т. Изявата на невралната пластичност може да промени баланса между възбудата и потискането в НС, да провокира хиперактивност и реорганизация на специфични части на $\mathrm{HC}$ или пренасочване на информация към части на $\mathrm{HC}$, които нормално не участват в обработване на звуците (нетрадиционни или екстралемнискални пътища).

- Обяснява появата на Т като отговор на невралната пластичност при лишаването от входни дразнители, поради слухови загуби или увреди на слуховия нерв.

Hendrickx JJ et all. (2007): B European multicentre study, проследяват 198 фамили и регистрират наличие на $\mathrm{T}$, който определят, че се дължи на влиянието на средата, в която всички живеят или на генетични фактори.

Mazurek B, Stöver T, Haupt H, Gross J, Szczepek A. (2007): Разглеждат ролята на кохлеарните невротрансмитери при tinnitus, като установяват:

- Патологични промени в кохлеарните невротрансмитери след експозиция на шум или отоксични медикаменти.

- Посочват, че прекомерното отделяне на глутамат (най-важния аферентен невротрансмитер във вътрешното ухо) води до възбуда и клетъчна смърт.

- Описват еферентните невротрансмитери dopamine и gamma aminobutyric acid (GABA) като инхибиторни, които могат да предпазят кохлеата от възбуждане, a acetylcholine (ACH) - редуцира гъстотата на външните слухови клетки и увеличава подвижността им.

- Описват Serotonin като невромодулатор на холинергичната и GABA ергичната инервация в кохлеята, който може да подтисне глутаматергичните импулси.

Mazurek B, Haupt H, Georgiewa P, Klapp BF, Reisshauer A (2007) проучват ролата на hypoxia и ischemia за генезата на tinnitus и акцентуират върху:

- Директната увреда на структурите на кохлеята, която води до загуба на слухови клетки и клетки на спиралния ганглий.

- Промяната на кръвотока, която предизвиква хипоксия исхемия.

- Невросензорният Т може да се дължи на: увреда на стереоцилиите, биохимични промени и промененото отделяне на глутамат.

- Промяната на кохлеарния кръвоток може да се провокира от експресията на отключващи гени като: nitrogen monoxide synthase and endothelin - 1, което води до Т.

Kaltenbach JA, Godfrey DA (2008):

- Представят все по-популярната през последните 10 години хипотеза за ролята на DCN (дорзалното кохлеарно ядро) като важен мозъчен център при генерирането и промяната на T.

- Описват този центьр като потенциален модел за проучване на механизмите на Т по отношение на клетъчните популации и детайлите на синапсите в областта на DCN.

\section{Tzounopoulos T (2008):}

- Прави извод, основан на последните наблюдения върху клетъчните механизми в дорзалното кохлеарно ядро, че отклоненията им могат да 
доведат до дълготрайни промени в синапсите между различните неврони в ядрото, което е предпоставка за зараждането и изявата на T.

Hendrickx JJetall. (2007): В European multicentre study, проследяват 198 фамили и регистрират наличие на $T$, който приемат, че се дължи на влиянието на средата, в която всички живеят, или на генетични фактори.

Baguley DM (2002): Разглежда последните теории и концепции, свързани с възприемането на T, и приема следните механизми на зараждането на tinnitus:

- Увреда на структурите на вътрешното ухо.

- Биохимични промени в слуховата система.

- Синхронизирана спонтанна активност в кохлеарния нерв.

\section{Литература:}

1. Noell CA, Meyerhoff WL. Tinnitus. Diagnosis and treatment of this elusive symptom. Geriatrics. 2003; 58(2): 28-34.

2. Marion MS, Cevette MJ. Tinnitus. Mayo Clin Proc. 1991; 66(6): 614 20 .

3. Zenner HP, Pfister M, Birbaumer N . Tinnitus sensitization: Sensory and psychophysiological aspects of a new pathway of acquired centralization of chronic tinnitus. Otol Neurotol. 2006; 27(8): 1054-63.

4. De Ridder D, Van de Heyning P. The Darwinian plasticity hypothesis for tinnitus and pain Prog Brain Res. 2007; 166: 55-60.

6. Saunders JC. The role of central nervous system plasticity in tinnitus.J. Commun Disord. 2007; 40/4/: 273-4

7. Müller AR. Neural plasticity in tinnitus, Prog Brain Res. 2006; 157 365-72

8. Müller AR. Tinnitus: presence and future.Prog Brain Res.2007; 166 3-16.

9. Müller AR. The role of neural plasticity in tinnitus. Prog Brain Res. 2007; 166: 37-45.

10. Kaltenbach JA, Godfrey DA. Dorsal cochlear nucleus hyperactivity and tinnitus: are they related? Am J Audiol. 2008; 17: 148-61.

11. Kaltenbach JA, Zhang J, Finlayson P Tinnitus as a plastic phenomenon and its possible neural underpinnings in the dorsal cochlear nucleus. Hear Res. 2005; 206(1-2): 200-26.

12. Richard Tylor, Claudio Coelho, William Noble. The influence of genetic factors on tinnitus. ORL; 2006; 68: 14-22

13. Tzounopoulos T. Mechanisms of synaptic plasticity in the dorsal cochlear nucleus: plasticity-induced changes that could underlie tinnitus.Am J Audiol. 2008; 17(2): 170-5

\section{Методи на лечение и повлияване}

- Все още няма трайно решение на проблема с $\mathrm{T}$.

- Поради разнообразните причини и механизми на зараждане на субективния Т няма общовалидно лечение, което се затруднява и от невъзможността за диференцирането им.

- Прилагат се медицински и немедицински средства и методи, но без особен ефект, като фармакотерапия, хирургични интервенции, когнитивна и поведенческа терапия, звукова и музикална терапия, TRT (Tinnitus retraining therapy), електрическа и магнитна супресия, масажи и други техники.

- Лечението на хроничния Т е насочено към привикване и ако е възможно - потискането му.

14. Hendrickx JJ, Huyghe JR, Demeester K, Topsakal V, Van Eyken E, Fransen E, Mäki-Torkko E, Hannula S, Jensen M, Tropitzsch A, Bonaconsa A, Mazzoli M, Espeso A, Verbruggen K, Huyghe J, Huygen PL, Kremer H, Kunst SJ, Manninen M, Diaz-Lacava AN, Steffens M, Parving A, Pyykkö I, Dhooge I, Stephens D, Orzan E, Pfister MH, Bille M, Sorri M, Cremers CW, Van Laer L, Van Camp G, Wienker TF, Van de Heyning P. Familial aggregation of tinnitus: a European multicentre study. B-ENT. 2007; 3; Suppl 7: 51-60

15. Baguley DM. Mechanisms of tinnitus. Br Med Bull.2002; 63: 195 212

16. Mazurek B, Stöver T, Haupt H, Gross J, Szczepek A. The role of cochlear neurotransmitters in tinnitusHNO. 2007; 55: 964-71

17. Mazurek B, Haupt H, Georgiewa P, Klapp BF, Reisshauer A. A model of peripherally developing hearing loss and tinnitus based on the role of hypoxia and ischemia. Med Hypotheses. 2006; 67(4): 892-9.

18. Jastreboff PJ, Hazell JW. A neurophysiological approach to tinnitus: clinical implications. Br J Audiol. 1993; 27(1): 7-17.

19. Jastreboff PJ. Tinnitus retraining therapy. Prog Brain Res. 2007; 166: 415-23

20. Jastreboff PJ, Jastreboff MM. Tinnitus retraining therapy: a different view on tinnitus. ORL J Otorhinolaryngol Relat Spec. 2006; 68(1): 23 9.

21. Hazell JW, Wood SM, Cooper HR, Stephens SD, Corcoran AL, Coles RR, Baskill JL, Sheldrake JB. A clinical study of tinnitus maskers. Br J Audiol. 1985; 19(2): 65-146. 